\title{
THE EFFECT OF UNILATERAL SPONTANEOUS PNEUMOTHORAX ON THE CIRCULATION IN MAN
}

\author{
BY HAROLD J. STEWART AND ROBERT L. BAILEY, JR. \\ (From the New York Hospital and Department of Medicine, Cornell University Medical \\ College, New York)
}

(Received for publication October 20, 1939)

The effect of artificial pneumothorax on cardiac output in animals has been studied by several investigators. Dogs have not been suitable as experimental animals because of the flimsy and often perforated mediastinum. In both the rabbit and the goat the mediastinum is intact, but the goat is the more satisfactory because of its size, larger blood volume, and the apparent similarity of its mediastinum to that of man. Among the recent work on the subject is that of Hilton (1). He selected goats as experimental animals and made use of the Fick principle for estimation of cardiac output. He found that a small unilateral pneumothorax gave rise to a slight increase in cardiac output but that a unilateral pneumothorax of moderate size resulted in a reduction in cardiac output of about 30 per cent. He suggested on the one hand that the initial increase in cardiac output was caused by the increased inspiratory efforts and probably anoxemia, and on the other that the decrease after induction of larger pneumothorax was due to diminished mechanical efficiency of breathing and consequent interference with the venous return to the heart.

Several reports have been made on the effect that pneumothorax has on cardiac output in man. The subjects for most of these investigations have been patients suffering from parenchymal pulmonary disease, usually pulmonary tuberculosis. Richards, Riley, and Hiscock (2) studied three young men exhibiting unilateral pulmonary tuberculosis before and after the induction of unilateral pneumothorax. In measuring cardiac output they used a method employing the Fick principle. In all three patients they observed fall in level of cardiac output on institution of unilateral pneumothorax.

Cournand, Bryan, and Richards (3) used a method similar to the one employed by Richards, Riley, and Hiscock (2) but exercised particular care in securing the venous and arterial carbon dioxide values. They made measurements of cardiac output when the lungs were expanded as well as during various stages of collapse in three patients suffering from pulmonary tuberculosis, in one having a lung abscess and in two exhibiting spontaneous pneumothorax. In three instances unilateral pneumothorax was associated with substantial decrease in cardiac output. In the remaining three cases, however, there was no consistent relation between the cardiac output and the degree of collapse. Since, however, the two cases of spontaneous pneumothorax were not studied after the lungs had completely re-expanded, control levels were not obtained in them. They inferred that in unilateral pneumothorax there was a tendency to diminished cardiac output which might be marked, slight, or absent. They suggested that pulmonary blood flow might be related more to the degree of ventilation of the collapsed lung than to the degree of collapse and that the motion of the diaphragm might have an important influence.

Nylin (4) used the acetylene method of Grollman in studying two cases both before and at intervals during the collapse of one lung by induced unilateral pneumothorax. Both patients suffered from pulmonary tuberculosis. In neither case did he observe progressive or consistent change in the cardiac output as unilateral pneumothorax was established.

Prikryl (5) studied five patients in whom he used the method of Grollman for the estimation of cardiac output. The patients were afebrile when estimations were made and basal conditions were observed. In four cases studied before and after the collapse of one lung, he found a slight decrease in cardiac output $(8,9,6$, and 1 per cent). In a fifth case, there was a slight increase (3 per cent). He considered these variations to be within the limits of normal fluctuation and ex- 
perimental error and concluded that cardiac output was not decreased by collapse of one lung.

The observations now being reported concern four patients who suffered unilateral spontaneous pneumothorax. Studies were made on them during various stages of collapse and after complete re-expansion of the lung. These patients appeared particularly suitable for this investigation because they were in good health when spontaneous pneumothorax occurred, because they had no evidence of pulmonary disease or organic heart disease, because there was no fluid in the pleural cavity, and because they were able to cooperate fully in carrying out the procedures. There were no signs of lung fistula. Studies were carried out during various stages of collapse of the lung and after complete re-expansion.

\section{METHODS}

All observations were made in the morning while the patients were in a basal metabolic state. Measurements of the cardiac output were made by the acetylene method, three samples of gas being taken as first recommended by Grollman (6), and as further elaborated by Grollman, Friedman, Clark and Harrison (7). During this measurement the patients were sitting in a steamer chair (angle $135^{\circ}$ ) with legs extended. They were acquainted with and trained to carry out the procedures beforehand. While the patient was at rest the cardiac rate was counted at intervals of five minutes. At the end of one hour the acetylene-air-oxygen mixture was rebreathed. Three samples of gas were taken during each rebreathing period for estimation of the arteriovenous oxygen difference. The first sample was taken after rebreathing ten to twelve times in twenty seconds, the second after two to three breaths more, and the third after two to three additional breaths. All three samples were usually obtained before the end of thirty seconds. Samples were taken during expiration. Two periods of rebreathing were carried out on each patient. Shortly afterwards the oxygen consumption was measured with a Benedict-Roth spirometer. After a short pause, the vital capacity was measured and height and weight determined. In succession, sufficient time being allowed between each procedure for the patient to return to a basal metabolic state, an electrocardiogram including a chest lead was taken, the arm-to-tongue circulation time recorded, the venous pressure estimated, and the blood pressure measured. Finally, the basal state still being maintained, a roentgenogram of the heart was made at a distance of two meters. The percentage of collapse of the lung was estimated by measuring with a planimeter the area of the shadow of the collapsed lung on the roentgenogram and the area of that part of the chest cavity normally filled by the lung when expanded. We realized that this method of esti- mating percentage collapse of the lung was not exact since it did not take into account the changes in the other planes. It was considered satisfactory, however, for a rough correlation. The three standard leads of the electrocardiogram were taken in each instance, and also in the case of H. H. and H. G. electrocardiograms were recorded with the patient supine, lying on the right side and lying on the left side, in order to calculate the shift of the electrical axis with change in position.

The arm-to-tongue circulation time was estimated by the use of decholin (8). Five cc. of a 20 per cent solution were injected rapidly (one to two seconds) through an 18 gauge needle into an antecubital vein while the patient was lying quietly in the supine position. This was repeated one and one-half minutes after the response to the first test had been elicited. The time was recorded from the beginning of the injection until the patient perceived the bitter taste.

The venous pressure was measured by the direct method (9), using a large antecubital vein, the arm being placed on a level with the right auricle. The system was filled with normal saline and the venous pressure read directly from a millimeter rule as millimeters of saline. Normal pressures by this method range from 40 to $100 \mathrm{~mm}$. of saline. In subsequent measurements the vein was entered at the site first punctured, the vein of one arm being reserved for measurement of venous pressure, and of the other arm for estimation of the circulation time.

Roentgenograms of the heart were taken with the patient in the standing position, in full inspiration, at a distance of two meters. Measurements of the cardiac area were carried out by the technique of Levy (10).

In one patient ( $T$. C.) estimations of the oxygen content of the blood were made. Samples of arterial blood were taken under albolene from a radial or brachial artery, and of venous blood, without stasis, from an antecubital vein, the same vein being used for this purpose each time. The oxygen content of these samples was estimated by the Van Slyke and Neill manometric method (11). Samples of blood were taken in the morning before breakfast with the patient in a basal metabolic state.

\section{OBSERVATIONS}

The data are recorded in Table $\mathrm{I}$.

Case H. H. was studied first when he showed 77 per cent collapse of the right lung, again when there was 34 per cent collapse, and finally after complete expansion (Table I). The cardiac output increased from 1.91 to 2.74 and finally to 3.0 liters per minute as the pneumothorax disappeared. The arteriovenous oxygen difference decreased. The arm-to-tongue circulation time decreased slightly. The venous pressure decreased slightly. Roentgenogram showed presence of the pneumothorax and slight displacement of the heart to the left. This displacement disappeared as the 
TABLE I

The effect of unilateral preumothorax on certain measurements of the circulation

\begin{tabular}{|c|c|c|c|c|c|c|c|c|c|c|c|}
\hline \multirow{2}{*}{ 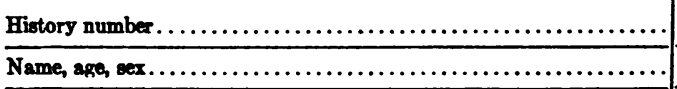 } & \multicolumn{3}{|c|}{ No. 213893} & \multicolumn{3}{|c|}{ No. 70382} & \multicolumn{3}{|c|}{ No. 217112} & \multicolumn{2}{|c|}{ No. 163478} \\
\hline & \multicolumn{3}{|c|}{ F.H. 47 years o } & \multicolumn{3}{|c|}{ T.C. 32 years or } & \multicolumn{3}{|c|}{ H.H. 43 years O' $^{7}$} & \multicolumn{2}{|c|}{ H.G. 29 years $\sigma^{7}$} \\
\hline Collapeed lung. ......... & \multicolumn{3}{|c|}{ Right } & \multicolumn{3}{|c|}{ Right } & \multicolumn{3}{|c|}{ Right } & \multicolumn{2}{|c|}{ Left } \\
\hline 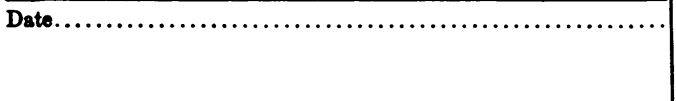 & $\begin{array}{c}\text { No- } \\
\text { vember } \\
5 \\
1938\end{array}$ & $\begin{array}{c}\text { No- } \\
\text { vember } \\
14 \\
1938\end{array} \mid$ & $\begin{array}{c}\text { De- } \\
\text { cember } \\
2, \\
1938\end{array}$ & $\begin{array}{c}\text { No- } \\
\text { vembe } \\
23, \\
1934\end{array}$ & $\begin{array}{c}\text { No- } \\
\text { vember } \\
30 \\
1934\end{array} \mid$ & $\begin{array}{l}\text { Janu- } \\
\text { ary } \\
12, \\
1935\end{array}$ & \begin{tabular}{|c|} 
No- \\
vember \\
3 \\
1938
\end{tabular} & \begin{tabular}{c|} 
No- \\
vember \\
26 \\
1938
\end{tabular} & $\begin{array}{c}\text { Feb- } \\
\text { ruary } \\
7 \\
1939\end{array}$ & $\begin{array}{c}\text { No- } \\
\text { vember } \\
29, \\
1937\end{array}$ & $\begin{array}{c}\text { April } \\
15, \\
1939\end{array}$ \\
\hline 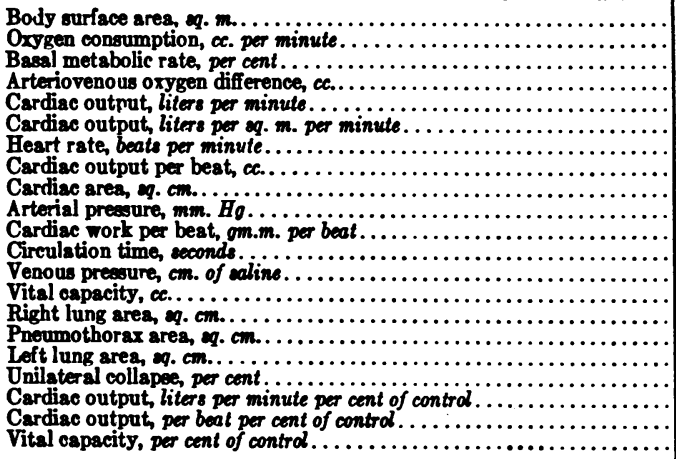 & \begin{tabular}{|l|}
1.70 \\
216 \\
-2 \\
77.1 \\
2.80 \\
1.27 \\
90 \\
31 \\
137.6 \\
$100 / 64$ \\
48.2 \\
20.4 \\
3.1 \\
2000 \\
220.5 \\
124.6 \\
279.5 \\
38 \\
90 \\
70 \\
55
\end{tabular} & \begin{tabular}{|l|}
1.77 \\
205 \\
-10 \\
57.1 \\
3.59 \\
2.03 \\
78 \\
46 \\
152.6 \\
$118 / 80$ \\
61.9 \\
19.9 \\
3.4 \\
3200 \\
295.3 \\
46.6 \\
283.5 \\
14 \\
115 \\
108 \\
90
\end{tabular} & \begin{tabular}{|l|}
1.82 \\
195 \\
-17 \\
60.6 \\
3.12 \\
1.77 \\
72 \\
43 \\
148.3 \\
$110 / 82$ \\
56.1 \\
19.0 \\
5.1 \\
3600 \\
300.7 \\
0 \\
286.1 \\
0 \\
100 \\
100 \\
100
\end{tabular} & \begin{tabular}{|l|}
.72 \\
203 \\
-13 \\
63.4 \\
3.20 \\
1.86 \\
88 \\
36 \\
135.3 \\
$130 / 78$ \\
50.9 \\
13.6 \\
16.3 \\
2600 \\
132.4 \\
175.2 \\
217.5 \\
57 \\
98 \\
80 \\
62
\end{tabular} & \begin{tabular}{|l|}
1.73 \\
216 \\
-9 \\
76.9 \\
2.81 \\
1.62 \\
88 \\
32 \\
32 \\
139.5 \\
$1126 / 74$ \\
43.5 \\
12.4 \\
10.8 \\
3000 \\
174.2 \\
132.4 \\
227.7 \\
44 \\
86 \\
70 \\
71
\end{tabular} & $\begin{array}{l}1.77 \\
211 \\
-12 \\
64.5 \\
3.28 \\
1.85 \\
72 \\
46 \\
128.4 \\
134 / 80 \\
66.9 \\
17.3 \\
4.8 \\
4200 \\
277.3 \\
0 \\
224.4 \\
0 \\
100 \\
100 \\
100\end{array}$ & \begin{tabular}{|l|}
1.74 \\
207 \\
-9 \\
107.9 \\
1.91 \\
1.10 \\
96 \\
20 \\
125.6 \\
$150 / 98$ \\
33.7 \\
12.3 \\
6.3 \\
2000 \\
68.2 \\
231.7 \\
259.0 \\
77 \\
64 \\
50 \\
57
\end{tabular} & \begin{tabular}{|l|}
1.78 \\
197 \\
-15 \\
73.0 \\
2.74 \\
1.54 \\
74 \\
37 \\
126.6 \\
$130 / 80$ \\
54.8 \\
11.6 \\
6.1 \\
2600 \\
207.5 \\
104.6 \\
261.9 \\
34 \\
91 \\
90 \\
74
\end{tabular} & $\begin{array}{l}1.79 \\
201 \\
-15 \\
69.1 \\
3.00 \\
1.70 \\
72 \\
42 \\
127.0 \\
118 / 76 \\
55.4 \\
9.5 \\
5.5 \\
3500 \\
264.7 \\
0 \\
246.7 \\
0 \\
100 \\
100 \\
100\end{array}$ & $\begin{array}{l}1.64 \\
228 \\
0 \\
75.2 \\
3.03 \\
1.85 \\
89 \\
34 \\
123.7 \\
85 / 50 \\
31.4 \\
7.6 \\
5.8 \\
2300 \\
245.5 \\
200.4 \\
75.5 \\
73 \\
87 \\
80 \\
61\end{array}$ & $\begin{array}{l}1.80 \\
234 \\
-4 \\
67.3 \\
3.48 \\
1.93 \\
80 \\
44 \\
123.9 \\
104 / 60 \\
49.1 \\
12.1 \\
6.7 \\
3800 \\
255.6 \\
0 \\
231.0 \\
0 \\
100 \\
100 \\
100\end{array}$ \\
\hline
\end{tabular}

lung expanded, while the vital capacity increased from $2000 \mathrm{cc}$., to $2600 \mathrm{cc}$., to $3500 \mathrm{cc}$. Electrocardiograms taken with the patient supine, lying on the right side, and lying on the left side showed only slight changes in deviation of the electrical axis with change in position.

Case H. G. was studied first when the left lung was collapsed 73 per cent and again after complete expansion. The cardiac output increased from 3.03 to 3.48 liters per minute. There was a moderate decrease in the arteriovenous oxygen difference. The arm-to-tongue circulation time increased from 7.6 to 12.1 seconds. The venous pressure increased slightly. Roentgenogram showed no appreciable displacement of the heart. The vital capacity increased from $2300 \mathrm{cc}$. to 3800 cc. Electrocardiograms were taken with the patient supine, lying on the right side, and lying on the left side. There was a slight left axis deviation during the period of pneumothorax which later disappeared. However, the electrical axis shifted more with change in position during the period of pneumothorax than it did later.

Case F. H. was studied first with 38 per cent collapse of the right lung, later with 14 per cent collapse, and finally after complete expansion. The cardiac output increased from 2.80 liters per minute with 38 per cent collapse, to 3.59 liters per minute with 14 per cent collapse and then decreased to 3.12 liters per minute after the pneumothorax had disappeared. Unlike the other patients this case achieved his largest cardiac output while there was partial collapse of one lung. Arteriovenous oxygen difference also was lowest at the time of 14 per cent collapse of one lung. The arm-to-tongue circulation time did not vary appreciably. The venous pressure showed a moderate increase but remained within normal limits. The roentgenogram showed the pneumothorax on the right and a slight shift of the heart to the left that disappeared as the lung expanded. The vital capacity increased from $2000 \mathrm{cc}$. to $3200 \mathrm{cc}$. and finally to $3600 \mathrm{cc}$. Electrocardiograms consisting of the three standard leads and a chest lead showed a slight shift of the electrical axis to the right and a slight increase in the amplitude of the $T$-wave in the chest lead as the heart resumed its normal position.

Case T. C. was studied first when there was 57 per cent collapse of the right lung, again when there was 44 per cent collapse, and finally after complete expansion. The cardiac output measured 3.20 liters per minute with 57 per cent collapse, decreased to 2.81 liters per minute with 44 per cent collapse, and increased to 3.28 liters per minute after complete expansion. Unlike the other patients, this case had a smaller cardiac output when there was a moderate degree of col- 
lapse than when there was more extensive collapse. The arteriovenous oxygen difference increased and then decreased as the lung expanded, being greatest at the time of 44 per cent collapse. The arm-to-tongue circulation time decreased slightly and then increased as the pneumothorax decreased but stayed within normal limits. The venous pressure was definitely elevated at the time of 57 per cent collapse but showed a substantial fall at each of the subsequent examinations. The roentgenogram showed a slight shift of the heart to the left at the time of maximum collapse but it was seen to be in normal position as pneumothorax decreased. The vital capacity increased from $2600 \mathrm{cc}$., to $3000 \mathrm{cc}$., and finally to $4200 \mathrm{cc}$. Electrocardiograms consisting of the three standard leads and a chest lead showed a slight shift of the electrical axis to the left as the heart returned to its normal position with expansion of the lung.

\section{DISCUSSION}

The decrease in cardiac output for individual patients showed no close correlation with the amount of pneumothorax. Two patients showed a moderate decrease in the presence of unilateral collapse; another achieved a larger cardiac output with a small pneumothorax than was present either in the control period or with greater collapse; yet another patient attained a smaller cardiac output with a moderate collapse than when there was more extensive pneumothorax. In all patients the basal metabolic rate was normal but on the low side of normal. In two patients (T. C. and H. G.) it changed only slightly as percentage collapse decreased. Case F. H., however, exhibited a fall from -2 per cent to -10 per cent to -17 per cent as the lung expanded; and Case H. H. showed a decrease in the basal metabolic rate from -9 per cent to -15 per cent. This change in the basal metabolic rate paralleled the slowing of the heart rate which occurred in these two cases. The fall in basal metabolic rate in these last two cases (F. H. and H.H.) accounted to some extent for the absence of a more substantial increase in their cardiac output. Nevertheless when percentage collapse was plotted against per cent of control cardiac output, for all patients, a rough linear correlation was seen, and the slope of the line was such that the greatest

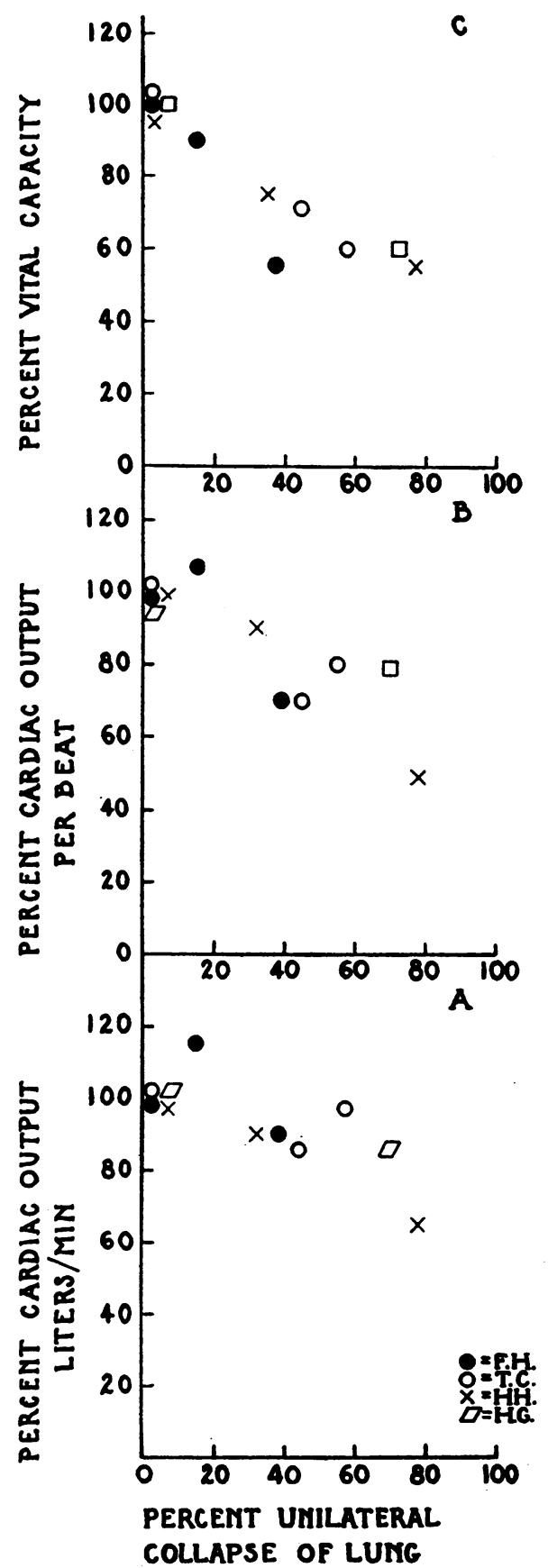

Fig. 1. Collapse of Lung and Cardiac OUtput and Vital Capacity

In this figure all observations of cardiac output per minute (A), output per beat (B), and vital capacity (C) as per cent of the levels when the lung had expanded completely, are plotted against the corresponding per cent collapse of the lung (Table I). This discloses a correlation which appears to be linear in that, as the amount of collapse increases, the cardiac output and vital capacity decrease. 
collapse was associated with the lowest cardiac output (Figure 1). The small collapse which was associated with increase in cardiac output will be discussed later. Similarly, there was a rough correlation between cardiac output per beat and amount of collapse, since the cardiac output per beat increased as the per cent of collapse decreased. There was no constant correlation between arteriovenous oxygen difference and degree of pneumothorax. The heart rate in each of the patients became slower as the pneumothorax disappeared. The arm-to-tongue circulation time showed no consistent change; in one case there was no change, in two there was an increase, and in the fourth there was a slight decrease as the lung expanded. The venous pressure was within or near normal limits and showed only slight changes except in the case of T. C. in whom there was a considerable fall from $16.3 \mathrm{~cm}$. to $4.8 \mathrm{~cm}$. of saline. The vital capacity varied inversely with the degree of collapse, and the correlation appeared to be linear (Figure 1).

Since the cardiac output appears to be reduced when a sufficiently large unilateral collapse of a lung occurs, by what mechanisms does the organism compensate for this reduction? There are data relating to one mechanism in the case of one patient. Measurements of the oxygen content of the arterial and venous blood were made of T. C. During collapse the arterial oxygen saturation was reduced to 92.3 per cent and 93.5 per cent, respectively (Table II), and restoration to a normal level, namely 97.5 per cent, occurred with complete expansion of the lung. The reduction in saturation during collapse may be accounted for by the mixture of blood of reduced oxygen content leaving the partially collapsed lung with normally oxygenated blood from the opposite normal lung. One of the mechanisms achieved by this patient was to raise the oxygencarrying capacity of the blood by increasing the amount of hemoglobin as much as 8 to 12 per cent (Table II) over what it was after re-expansion of the lung. It was possible for him to maintain his normal range of oxygen utilization during collapse (Table II).

Although roentgenograms showed slight displacement of the heart to the side opposite the pneumothorax in each case, the electrocardiograms showed no consistent deviation of the electrical axis. Moreover, as the pneumothorax disappeared and the heart returned to normal position, the electrical axis shifted in a direction similar to that of the heart in two cases but in the opposite direction in the other two cases. Rotation of the heart, which could not be demonstrated on anteroposterior roentgenograms, doubtless accounted for this inconsistency.

In only one of the patients (Case F. H.) were studies of the circulation performed in the presence of a unilateral pneumothorax as small as 14 per cent. The results here were similar to those found by Hilton (1) in his observations on goats in that there was an increase in cardiac output with this small amount of collapse of one lung. The patient showed neither cyanosis nor dyspnea, but the rate of respiration was slightly more rapid at the time of this measurement than after the pneumothorax had disappeared. From our data and those reported in the literature, it appears that, in the presence of a unilateral pneumothorax of small or moderate size, there is likely

TABLE II

Changes in blood gases during unilateral collapse in T.C.

\begin{tabular}{|c|c|c|c|c|c|c|c|c|c|c|}
\hline Date & $\begin{array}{l}\text { Uni- } \\
\text { lateral } \\
\text { collapse }\end{array}$ & $\begin{array}{l}\text { Oxygen } \\
\text { content } \\
\text { arterial } \\
\text { blood }\end{array}$ & $\begin{array}{l}\text { Oxygen } \\
\text { content } \\
\text { venous } \\
\text { blood } \\
(\text { arm })\end{array}$ & $\begin{array}{l}\text { Oxygen } \\
\text { capacity } \\
\text { venous } \\
\text { blood }\end{array}$ & $\begin{array}{l}\text { Hemo- } \\
\text { globin } \ddagger\end{array}$ & $\begin{array}{c}\text { Arterial } \\
\text { oxygen } \\
\text { saturation }\end{array}$ & $\begin{array}{c}\text { Venous } \\
\text { oxygen } \\
\text { saturation }\end{array}$ & $\begin{array}{l}\text { Arterio- } \\
\text { venous } \\
\text { oxygen } \\
\text { difference }\end{array}$ & $\begin{array}{c}\text { Oxygen } \\
\text { content } \\
\text { mixed } \\
\text { venous } \\
\text { blood* }\end{array}$ & $\begin{array}{c}\text { Oxygen } \\
\text { utiliza- } \\
\text { tiont }\end{array}$ \\
\hline & per cent & $\begin{array}{c}c c . \text { per } \\
\text { liter }\end{array}$ & $\begin{array}{c}\text { cc. per } \\
\text { liter }\end{array}$ & $\begin{array}{c}\text { cc. per } \\
\text { liter }\end{array}$ & per cent & per cent & per cent & $\begin{array}{c}c c . \text { per } \\
\text { liter }\end{array}$ & $\begin{array}{c}\text { cc. per } \\
\text { liter }\end{array}$ & per cent \\
\hline $\begin{array}{l}\text { November } 23,1934 \\
\text { November } 30,1934 \\
\text { January } 12,1935\end{array}$ & $\begin{array}{r}57 \\
44 \\
0\end{array}$ & $\begin{array}{l}209.0 \\
218.0 \\
206.0\end{array}$ & $\begin{array}{l}163.0 \\
127.0 \\
138.0\end{array}$ & $\begin{array}{l}229.0 \\
236.0 \\
215.0\end{array}$ & $\begin{array}{l}112.4 \\
116.2 \\
104.9\end{array}$ & $\begin{array}{l}92.3 \\
93.5 \\
97.5\end{array}$ & $\begin{array}{l}71.2 \\
52.1 \\
63.4\end{array}$ & $\begin{array}{l}63.4 \\
76.9 \\
64.5\end{array}$ & $\begin{array}{l}145.6 \\
131.1 \\
141.5\end{array}$ & $\begin{array}{l}28 \\
33 \\
30\end{array}$ \\
\hline
\end{tabular}

* Derived by subtracting arteriovenous oxygen difference from oxygen content of arterial blood.

+ Ratio between arteriovenous oxygen difference and oxygen capacity.

$\ddagger 185$ cc. per liter $=100$ per cent hemoglobin. 
to be a slight reduction in cardiac output not only when there is no pulmonary pathology, as in our cases, but also in the presence of pulmonary disease. There may, however, be no changes in cardiac output or even an increase. When collapse is more nearly complete, however, most cases show reduction in cardiac output which may be large or small.

\section{SUMMARY}

1. Certain studies were made of the circulation of four patients exhibiting unilateral spontaneous pneumothorax of unknown etiology. None of the patients showed either demonstrable pulmonary pathology or organic heart disease. Studies were made at various levels of collapse and after complete expansion.

2. The cardiac output appeared to be reduced in the presence of unilateral pneumothorax of small or moderate size, although it was sometimes unchanged or even increased. Patients exhibiting more extensive pneumothorax showed a reduction in cardiac output which might be large or small. When the data for all cases were pooled, a rough linear correlation appeared between both cardiac output per minute and per beat, and per cent collapse of the lung, since the greatest collapse was associated with the greatest decrease in cardiac output; as the amount of collapse decreased, the cardiac output increased. In one of our patients who was observed during collapse of only 14 per cent, there was an increase in cardiac output. This finding is similar to one made by Hilton (1) in goats, namely, that a small collapse gives rise to an increase in volume output of blood from the heart.

3. The decrease in vital capacity bears a linear relation to the per cent collapse of the lung.

4. Since unilateral collapse of a lung usually results in decrease in the volume of blood expelled by the heart per minute, the institution of this procedure should be considered carefully before it is undertaken in subjects suffering from lesions which may themselves be associated also with decrease in output. This precaution is necessary in order to avoid an accumulated reduction in cardiac output.

\section{BIBLIOGRAPHY}

1. Hilton, R., Some effects of artificial pneumothorax on the circulation. J. Path. and Bact., 1933, 37, 1.

2. Richards, D. W., Riley, C. B., and Hiscock, M., Cardiac output following artificial pneumothorax in man. Arch. Int. Med., 1932, 49, 994.

3. Cournand, A., Bryan, N. A., and Richards, D. W., Jr., Cardiac output in relation to unilateral pneumothorax in man. J. Clin. Invest., 1935, 14, 181.

4. Nylin, G., Untersuchungen über das Minutenvolumen des Herzens in 2 Fällen mit einseitigen künstlichem Pneumothorax. Britr. z. Klin. d. Tuberk., 1933, 83, 470.

5. Přikryl, Z., Uliv umeliho pneumothoraxu na minutouy objem srdecni. Spisy Lekarske Fakulty Masanykouy University, 1936, 15, 141.

6. Grollman, A., The Cardiac Output in Man in Health and Disease. C. C. Thomas Company, Springfield, 1932, p. 73.

7. Grollman, A., Friedman, B., Clark, G., and Harrison, T. R., Studies in congestive heart failure. XXIII. A critical study of methods for determining the cardiac output in patients with cardiac disease. J. Clin. Invest., 1933, 12, 751.

8. Tarr, L., Oppenheimer, B. S., and Sager, R. B., The circulation time in various clinical conditions determined by the use of sodium dehydrocholate. Am. Heart J., 1933, 8, 766.

9. Taylor, F. A., Thomas, A. B., and Schleiter, H. G., A direct method for the estimation of venous blood pressure. Proc. Soc. Exper. Biol. and Med., 1930, 27, 867.

10. Levy, R. L., The size of the heart in pneumonia; a teleoroentgenographic study, with observations on the effect of digitalis therapy. Arch. Int. Med., 1923, 32, 359.

11. Van Slyke, D. D., and Neill, J. M., The determination of gases in blood and other solutions by vacuum extraction and manometric measurement. J. Biol. Chem., 1924, 61, 523. 